\title{
State University Libraries and Regional Education
}

Mr. Grieder is librarian, West Virginia University.

\section{The Proposal for Regional Education}

$\mathrm{T}$ HE current discussions regarding the establishment of regional centers for postgraduate higher education involve a radical departure in American university organization. If the proposals on which this discussion is based materialize in action, the private, municipal, and individual state universities will be joined by a fourth type, the cooperative enterprise jointly administered and supported by several states, for the specific purpose of supplying facilities for graduate and professional education which no one state can provide adequately.

This idea originated in the South. A strong motivating influence was undoubtedly exercised by the desire to fulfill the requirements laid down by the courts in such cases as that of Ada Sipuel, a Negro student who attempted to enroll in the University of Oklahoma law school, without breaking down the existing segregation of white and Negro students. The law school created by the state of Oklahoma in response to the demand that it provide equal facilities for Negroes has been declared inferior to the school at the University. This general problem, which faces the South in many fields of instruction, was complicated by the fact that the administration of Meharry Medical College at Nashville recently announced that unless help on a large scale were obtained the school could no longer operate, since its private endowment and other income were insufficient to meet expenses. Meharry is the only medical school, other than that of Howard University, which offers extensive opportunities to Negroes, and its closing was at once recognized as a threat to the well-being of the South. The long-range problem of equal educational opportunity took on the character of an immediate crisis.

The first concrete measure toward its solution was the signing of a compact drawn up at a conference called by Governor Caldwell of Florida. Fifteen states participated: Alabama, Arkansas, South Carolina, Florida, Georgia, Maryland, Mississippi, Tennessee, Texas, Virginia, West Virginia, North Carolina, Kentucky, Louisiana, and Oklahoma. This compact is printed in the hearings of a Subcommittee of the Committee on the Judiciary of the United States Senate, Eightieth Congress, Second Session. The hearings, held on March 12 and 13 , I948, were called to consider S.J. Res. I9I, which provided for approval of the compact, a step which such interstate action requires. Included in the transcript is a brief history of the proposal embodied in the compact, from which the information in the following paragraphs is taken.

Briefly, the compact itself provides for the creation of a Board of Control for Southern Regional Education, "the members of which board shall consist of the governor of each 
state, ex-officio, and two additional citizens of each state to be appointed by the governor thereof, at least one of whom shall be selected from the field of education." The duties of the board are "to submit plans and recommendations to the states from time to time for their approval and adoption by appropriate legislative action for the development, establishment, acquisition, operation, and maintenance of educational schools and institutions within the geographical limits of the regional area of the states, of such character and type and for such educational purposes, professional, technological, scientific, literary, or otherwise, as they may deem and determine to be proper, necessary, or advisable." Title to such institutions would be vested in the board, and they would be supported jointly by the participating states in proportion to the populations as determined by the Bureau of Census, or on some other mutually satisfactory basis. Separate agreements between two or more states are permissible under the terms of the compact. There is, of course, much more to it than this; regulations are laid down for the adherence or withdrawal of states and the terms of office of board members are stated. The essence of the plan, however, lies in the provisions given above.

The racial problem is neither stated nor implied in the agreement. It naturally arose at the hearings, and tended somewhat to becloud consideration of the broader merits of the idea, as Governor Caldwell observed. On March 4 a conference at Gainesville was occupied with lengthy discussions regarding the general value of interstate cooperation in higher education. Owen D. Young, Dr. Oliver Carmichael, and Dr. Fred McCuistion strongly advocated it as a means of overcoming recognized deficiencies without reference to race. At the hearings Governor Caldwell spoke of the shortage of mining schools in the South, Dr. Raymond Paty of the lack of facilities for dental training, and Senator Johnston of the general need for technical institutions. All these men expressed the belief that cooperation offered much more than an expedient for continuing segregation. The following section is based on the opinion that the idea must be taken in the broadest application as a method of overcoming a serious lack of facilities for high-level research and professional training in many areas of the country.

\section{State University Libraries in Regional Groupings}

The exact effect of a regional development on existing state universities depends on the scope and character of new institutions. It is possible that some will find themselves resembling good undergraduate colleges, although a certain amount of graduate work will probably always have to be carried on in local schools, if only because many students and faculty members will continue to have local interests, such as the history or geology of particular states. It can scarcely be denied that regional universities will tend to minimize the growth of state universities in certain directions, a limitation which will be shared by libraries. In those areas of learning which are already well developed locally there is less likely to be a serious restriction; it will be felt more acutely in fields which are comparatively undeveloped.

Regional cooperation will exert its greatest appeal in those geographical areas which are most deficient in facilities for advanced postgraduate study, and between individual states the appeal will vary with the situation of the university. If the latter has several good schools in operation, the fields in which it will wish to cooperate will be fewer than if it has few or no graduate 
schools, in which case it will probably have also a library inadequate to support extensive graduate work. There are no exact quantitative or qualitative standards for a good research library, and it seems that an appraisal must always depend on what the university is attempting to do. The standards, in short, are relative rather than exact. It can be accepted, however, that the development of graduate work is limited by the collections available for students and faculty. Universities with small libraries are restricted in their undertakings, just as they are restricted by a lack of laboratories or other physical requirements. Therefore, a consideration of small state university libraries will provide at least a clue to those areas in which cooperative developments seem most likely to occur, and will point out the areas which seem most likely to profit by them.

As a starting point, the figures given in The American Library Directory, 1945, reveal that in 1944 the median library among forty-six state university collections possessed about 255,000 volumes. This figure is probably about 300,000 now, since Oklahoma, with 254,671 in 1944, had 280,978 in 1947 , and Florida had 246, I 18 and 292,396 in the same two years. ${ }^{1}$ For purposes of this discussion the below-median libraries will be considered "small," though a very good case can be made for regarding much larger collections as inadequate for extensive graduate programs. The catalogs of eleven of these institutions, scattered in all parts of the country, show that six of the eleven offer the degree of Ph.D., and three that of M.D. Three universities have one professional graduate school, in each case a two-year medical school; three have two professional graduate schools, and two have

1 I 947 figures are taken from Statistics of Southern 1947 figures are taken from Statistics of Southern
College and University Libraries, 1946-47. Baton Rouge, Louisiana State University Library, December 1947 . three. Three offer no such instruction. Graduate study at the doctoral level is generally limited to a few fields, while masters' work is offered in a great many. In view of present enrolments it is probable that all these small schools are subject to a good deal of pressure for expansion of their graduate and professional programs.

In connection with this last point, it is generally expected that enrolments at all levels will remain higher than they were before the war. Even though they may decline somewhat from present peaks, there is at least a short-term probability that demands for graduate instruction will be very heavy as veteran undergraduates progress in their studies. The following figures from West Virginia University do not prove a trend, but they illustrate a situation which one below-median library must face:

\begin{tabular}{clrrrr}
$\begin{array}{c}\text { Under- } \\
\text { classmen }\end{array}$ & $\begin{array}{l}\text { Per } \\
\text { Cent }\end{array}$ & $\begin{array}{c}\text { Upper- } \\
\text { classmen }\end{array}$ & \multicolumn{2}{c}{ Per } & \multicolumn{2}{c}{ Per } \\
2439 & 69.2 & 843 & 23.9 & 244 & 6.9 \\
4524 & 69.9 & 1496 & 23.1 & 453 & 7.0 \\
4162 & 60.0 & 2267 & 32.6 & 511 & 7.4
\end{tabular}

The figures for $1947-48$ show a decrease of 9.9 per cent in the proportion of underclassmen, with increases of 9.5 per cent and .4 per cent for upperclassmen and graduate students respectively, as compared with 1946-47. Considering that the total enrolment is about double that for 1939-40, a greatly increased pressure for all kinds of reading matter can be expected in the immediate future, and is already manifesting itself. Since the library has always been much better equipped for undergraduate than for graduate study, the emphasis of this demand will be on materials for advanced research. Speculation regarding more or less permanent levels of enrolment at various grades must be deferred until the evidence of a few more years is available.

Of the fifteen states which subscribed to the compact of February, eight have university libraries falling below the median 
size, and seven have libraries lying above it. There remain fifteen university libraries below the median and not yet concerned in regional planning. If the entire group of twenty-three below-median collections is analyzed the possibilities of regional grouping are striking. The universities to which they belong are not located in a single region, and in fact the fifteen Southern states can hardly be called that. They stretch from Texas to Maryland. Historically, economically, culturally, and sociologically they vary greatly. Their common factor is the presence in each state of a large Negro population.

Several logical groups emerge rather than one cohesive group. If to the twenty-three libraries a few lying just above the median are added, much strength is added to several groups. In the illustration below, the letter $a$ indicates universities with libraries of below-median size; $b$ indicates those with larger collections. The names of states which have subscribed to the compact are italicized. Several of these have large and excellent universities, and the degree to which they will wish to cooperate in undertakings not connected with Negro education is perhaps doubtful. They have at least expressed an interest in regional cooperative projects, and are therefore included in the listing.

A Regional Grouping of University Libraries

I. a. Maine, New Hampshire, Vermont, Massachusetts, Connecticut, Rhode Island (no university)

2. a. Maryland, Delaware, West Virginia,

Pennsylvania (no university)

b. Virginia

3. a. South Carolina, Georgia, Florida

b. North Carolina

4. a. Mississippi, Tennessee

b. Kentucky, Alabama

5. a. Arkansas, Oklahoma

b. Louisiana, Texas

6. a. North Dakota, South Dakota, Wyoming, Idaho

\section{b. Montana}

7. a. Nevada, Utah, Arizona, New Mexico

This division includes every university with a below-median library, and all the Southern states signing the compact. In these days of easy communication it is perhaps unnecessary to consider convenience of location unless accessibility is an important factor. This would be the case, for example, if professors at a regional institution were also expected to teach at a local university. The larger the groupings the more economically first-rate facilities could be provided. The alignment given above is thus intended less as a practical proposal than as an illustration of the possibilities which accidents of location offer for grouping the institutions which have most to gain from cooperative effort.

It is undoubtedly true that many of the institutions listed above are making efforts to expand their graduate programs. The difficulties which lie in their paths are indicated by the fact that of the twenty-three states with submedian libraries, seventeen fall below the median for state general revenues and for public library expenditures from state funds; and twenty fall below the median for state school expenditures. ${ }^{2}$ Massachusetts, Connecticut, and Pennsylvania, which are high in the ranking by revenues, are special cases. All have fine private universities, and all have had until recently state colleges. The first two have lately undertaken to form universities on these foundations, and Pennsylvania State College is actually a university in all but name. In descending the scale of libraries smaller state revenues are encountered. Universities having the smallest ten libraries are in states which rank from thirty downward in the revenue scale, except for Massa-

${ }^{2}$ U.S. Bureau of Census. State Finances, 1946. Compendium. Washington, Government Printing Office, 1947 . 
chusetts and Connecticut. It appears that the smaller the library the smaller the resources which can be expected for university development, as well as other governmental services.

\section{Summary}

The following points emerge regarding interstate cooperation in higher education with special reference to the state university libraries which might be involved:

I. The idea of regional cooperation in advanced levels of higher education, while strongly motivated by the desire to continue the practice of racial segregation, has gone beyond that objective. Its application to the general problem of providing university facilities which are not available in large areas of the country has been advocated and is permissible under the compact of February 8, 1948, between fifteen Southern states.

2. Figures for 1944 , with estimates to 1948 , show that about one-half the state university libraries of the country have less than 300,000 volumes. A considerable part of this group, on the basis of a sampling of eleven institutions, offers work up to the Ph.D. degree, and supports one or more graduate professional schools. It is obvious that for existing programs and for expansion these institutions are seriously handicapped with regard to library resources.

3. Enrolments are expected to remain at levels substantially higher than those of prewar years. On a short-term basis a larger proportion of upperclassmen and graduate students can be expected; on a long-term basis the predictions are more doubtful, though the higher general enrolment levels will mean increased demands for all reading materials. This pressure will be felt with special force in those collecting areas which are, and usually have been, given less attention in smaller universities. Such areas include the high-level research literature in a number of subject fields.

4. The twenty-three below-median libraries can be grouped into coherent regional divisions. The Southern states subscribing to the compact of February 8 fall into several groups rather than one. The remaining states, with the addition of a few possessing libraries just above the median size, can be similarly aligned. The institutions which support the libraries are likely to be those which also require extensive additions to their research facilities, and therefore have most to gain from cooperation with others in the same situation.

\section{Microprint Reader}

\section{(Continued from page 38 )}

cost between film and paper is insignificant except in the case of mass reproduction.

Whether in the end film or Microcards will prove more suitable for library use will depend not only on their relative degree of satisfactory performance and the rela- tive cost of production, maintenance, and use, but also upon the manner of distribution of microreproductions and reading machines, and, last but not least, upon their acceptance by the library user as substitutes for the printed page.

\section{Oregon Statutes \\ (Continued from page 40)}

are of such character that release is not practicable, in which case the same amount of time may be allowed at another date. Student recesses in addition to the days above named do not constitute institutional holidays.

\section{Professional Activities}

Administrative Code, K-19. No full-time employee in the Oregon State System of Higher Education or of any of the institutions thereof shall engage in any outside activity which substantially interferes with his regular duties. Prior to acceptance of any employment involving time or honorarium, the individual concerned shall secure the approval of the executive head of the institution. 